\title{
The interactive effect of gender, residence, and socioeconomic status on early sexual debut among sexually active young adults in Ghana
}

\author{
Kwaku Oppong Asante ${ }^{1,2, *}$, Edward Nketiah-Amponsah ${ }^{3}$, Johnny Andoh-Arthur ${ }^{1} \&$ Samuel \\ Ampaw 4 \\ ${ }^{1}$ Department of Psychology, University of Ghana, Legon, Accra, Ghana \\ ${ }^{2}$ Discipline of Psychology, University of the Free State, Bloemfontein, South Africa \\ ${ }^{3}$ Department of Economics, University of Ghana, Legon, Accra, Ghana \\ ${ }^{4}$ School of Economics, University of Nottingham Ningbo China, Ningbo, People's Republic of \\ China
}

\begin{abstract}
Aim: The objective of this study was to examine the interactive effect of gender, rural-urban residence, and socioeconomic status on early sexual debut among young adults in Ghana

Methods: The study used the 2014 Ghana Demographic and Health Survey with a sample of 2746 sexually active youth (males $=670$ and females $=2076$ ) aged $15-24$. We used multivariate logistic regression to analyse the data.

Results: Our results showed that female youth in urban areas and those from the wealthiest households were less likely to initiate early sexual debut. Additionally, youth resident in urban areas from rich households are less likely to initiate early debut. However, a-3 way interactive effect revealed that female youth resident in urban areas from rich households were found to be more likely to initiate early debut.
\end{abstract}

Conclusion: Our findings underscores that a gender-based sexual and reproductive health interventions and programmes may be more appropriate for adolescent females in rich households living in urban areas. These interventions should reach these teenagers before they start engaging in sexual intercourse.

Key word: Sexual debut; Young adults; Sexually active; HIV; Sexual behaviour; Ghana

* Correspondence: Kwaku Oppong Asante, Department of Psychology, University of Ghana, Legon, Accra, Ghana.Email: kwappong@gmail.com/kopppongasante@ug.edu.gh 


\section{Introduction}

Globally, early sexual activity remains a recurring public health issue as it marks the onset of exposure to infections and presents longer-term influences in the sexual lives and sexual health of young persons (Chow et al. 2017). The serious health risks associated with early sexual debut as well as the belief that the expression of sexuality is acceptable only in marriage, drives the promotion of sexual abstinence as a major reproductive health policy in many conservative societies across the globe (Santelli et al. 2006). Notwithstanding, there are increasing incidence of early sexual initiation among young adults than in the past decade (Amo-Adjei and Tuoyire 2018; Clark et al. 2017). Early sexual debut predisposes young adults to numerous negative sexual and reproductive health outcomes (Marston et al. 2013). It is reported that young adults who have early sexual debut at a younger age were more likely to engage in unprotected sexual intercourse and have concurrent multiple sexual partners (Onsomu et al. 2013; Marston et al. 2013). Early sexual intercourse has also been found to be associated with unwanted pregnancies and poor educational outcomes particularly for school-going adolescents (Peltzer, 2010). Furthermore, unwanted sexual consequences such as problems with orgasm and sexual arousal as well as poor psychosocial health outcomes including depression and low self-esteem in later life are all linked to early sexual intercourse (e Silva et al. 2016; Kastbom et al. 2015; Lara and Abdo 2016).

Key precursors to early sexual debut at the familial level include adolescent born to a teenage mother, family income and structure (França and Frio 2018; Lee et al. 2018), and maternal education (Rose et al. 2005). At the broader macro, social and cultural levels, religious norms regarding the immorality of sex outside of marriage, gender norms that emphasises motherhood, or cultural norms that undervalue adolescence as a stage of human development in some countries are noted to shape systems-level factors in early sexual behaviour and sexual and reproductive health care of young adults (Jesmin and Cready 2016; MacPherson et al., 2014). Often implicated in the gender differences in the early initiation of sexual intercourse are also cultural aspects regarding sexuality, which gives rise to the phenomenon of sexual double standardness, where the same sexual behaviour between male and females are given different interpretations in societies (Crawford and Popp, 2003; Kreager et al. 2016; Lyons et al. 2014). The situation, it is observed, allows males generally to have more sexual freedom making them come under more pressure from a young age to form and prove their masculinity through sexual activity, whereas girls experience more sexual restrictions (e Silva et al. 2016). 
In Africa, studies have established that several socio-demographic factors including being female, younger age, low socioeconomic status, rural residence (Ningpuanyeh and Susuman 2017; Asante et al. 2018; Zuma et al. 2010; Peltzer 2010) are independently associated with early sexual debut. Given the constellation of factors that contribute to the early sexual debut globally, a past study that utilized a resiliency approach suggested several paths to which early sexual debut and risky sexual behaviors develops and emphasized the need for investigating multiple instead of singular pathways (Lohman and Billings 2008). In spite of the evidence of the multifactorial nature of early sexual debut and the admonition to explore multiple pathways that gives form and expression to the behaviour, few studies have attempted to examine the interaction of these factors, specifically, key socio-demographic variables that have been consistently linked to the phenomenon particularly in Africa. A recent study conducted in Ghana found that belonging to a wealthier household was protective of early sexual debut for young females living in the urban areas but at the same time served as a risk factor for males living in rural areas (Asante et al. 2018). What remains unclear is how the collective effect of gender, residence and wealth status influences early sexual debut among sexually active young adults in Ghana. A study in Brazil for instance, found gender, the region of residence and type of schools as determining factors for sexual initiation but did not explore how the interaction of these factors contribute to the problem (Borges et al. 2016). Using the 2014 Ghana Demographic and Health Survey, this study examines the interactive effect of gender, rural-urban residence, and socioeconomic status on early sexual debut among young adults in Ghana. The current study add s to the trove of evidence on the phenomenon

of early sexual debut and its demographic correlates in Ghana. More specifically, findings have relevance for addressing specific needs of sexually active youth, taking in consideration also, how their lived socioeconomic and socio-spatial situations combine with their gender to either increase or decrease their vulnerabilities to early exposure to sex.

\section{Materials and methods}

\section{Sampling procedure and participants}

The 2014 Ghana Demographic Health Survey (GDHS) was conducted using a stratified two-stage cluster design consisting of 427 clusters, 216 in urban areas and 211 in rural areas. The first stage was a random selection of clusters, followed by a systematic selection of households in the second stage (Ghana Statistical Service, 2014). The survey successfully interviewed 11,835 households, 
yielding a response rate of 98.5\%. Moreover, 9,396 and 4,388 eligible females and males participated in the survey, producing response rates of $97.3 \%$ and $95.2 \%$ respectively. For the current study, early sexual debut was used to describe those who initiate sexual debut early, and this was derived from the variable age at first intercourse. Sexually active youths aged 15-24 years were used as the basis for analysis. Thus, the sample size of 2746 (males $=670$ and females $=$ 2076) was used for the current study.

\section{Procedure}

Data for this study was obtained from the 2014 Ghana Demographic and Health Survey (GDHS). The GDHS is a nationwide survey with a representative sample of women and men aged 15-49 and $15-59$, respectively $(N=13,784)$. The Ghana Statistical Service, the Ghana Health Service (GHS), and the National Public Health Reference Laboratory (NPHRL) of the GHS supervised the collection of the 2014 GDHS. Ethical approval for the study protocol was given by the Ghana Health Service Ethical Review Committee in Accra, Ghana and the Institutional Review Board of ICF International.The survey asked households questions related to HIV testing. Besides the HIV testing, individuals were asked to state their age at first intercourse during the last 12 months. Moreover, socio-demographic key indicators such as age, sex, place of residence, region, religion, education level, and ethnicity were also part of the questions in the questionnaires. Each household selected for the GDHS was eligible for interview with the household questionnaire. Data collection was carried out by the 25 field teams from early September to mid-December 2014. Senior staff members from the Ghana Statistical Service and the Ghana Health Service coordinated and monitored the fieldwork. Paper questionnaires were used to conduct the interviews. After the interviews, field editors entered the questionnaire data into laptops, using password s to protect the files. Electronic data files were transferred to the central office every few days via the secured Internet File Streaming System (IFSS). Fieldwork monitoring was carried out by staff of GSS, GHS, and two survey technical specialists from The DHS Program. Data collection took 3.5 months. 


\section{Measures}

Dependent variable: The study uses age at first intercourse from the survey data, and respondents who initiate sexual debut before the age of 16 years were described as "early sexual debut." This was considered as the dependent variable.

Independent variables: The independent variables used in this study were selected based on previous studies (Asante et al. 2018; Ningpuanyeh and Susuman 2017; Peltzer 2010). These include our treatment variables namely place of residence (urban and rural), gender (males and females) and household wealth, represented by wealth index (in three categories from poor, average to rich). The wealth index was constructed using data on a household's ownership of selected assets, such as televisions and bicycles, materials used for housing construction, and types of water access and sanitation facilities. The index places individual households on a continuous scale of relative wealth. It was then categorized into three categories from poor, average to rich.

\section{Statistical analyses}

The weighted data was analysed using STATA 14.1, which accounted for the sample strata, the primary sampling unit and population weights. Multivariate logistic regression analyses were conducted to determine the interactive effect of gender, residence, and wealth status on early sexual debut among sexually active young adults in Ghana. For robust estimates, the analysis was performed at different levels. Also, cluster-robust standard errors were used. The first consideration was estimating the three variables in pairs and jointly, yielding four different models (labelled Model 1-4). This was to explore the sensitivity of the results to include both the wealth status and residence variables since the results from a pairwise correlation showed that the two variables have a highly significant positive association $(p<0.001)$. Subsequently, for each model, we estimated a parsimonious version where other control variables were excluded, and another with the inclusion of other control variables selected with recourse to related empirical literature.

Generally, following applied micro-econometrics literature, one would expect the model with more control variables to yield the most efficient and unbiased estimators since the parsimonious models in our case are likely to suffer from omitted variable biases. The results labeled Model 4b in Table 1 is chosen for our discussion because it controls for most of the relevant variables.The results from the logistic regression analyses are presented as odds ratios (OR) with 
95\% Confidence Intervals (CIs). Statistical significance was defined as a two-tailed $p$ value $<0.05$ in all analyses. The regression model with all control variables are presented in Table 3 as supplementary material.

\section{Results}

\section{Demographic characteristics of the sample}

The demographic characteristics of the participants are presented in Table 1. The majority of the participants $(75.6 \%)$ were females and the remaining $24.4 \%$ being males. Participants with ages between 20 and 24 comprised $66.5 \%$ of the sample and the remaining $33.5 \%$ were for participants between 15 and 19 years. The majority of the participants had at least secondary education (71.8\%), had not tested for HIV (63.0\%) and had not used any modern contraceptive methods $(69.3 \%)$. Over half of the participants (58.2\%) were employed and lived in rural areas (54.2\%). About $45 \%$ of the participants considered themselves to be poor and approximately one-third (30.9\%) were considered as rich. Approximately $77 \%$ of the participants were Christians, $18.2 \%$ were Muslim, and the remaining $5.1 \%$ belonged to other religious affiliations. The sample also indicated that about $72.1 \%$ had partial access to media and over $42 \%$ belong to the Akan ethnic group.

\section{[INSERT TABLE 1 HERE]}

\section{Interactive effect of once gender, residence, and wealth on early sexual debut}

Female youth, those resident in urban areas, and those affiliated with households in the upper third of wealth status were more likely to initiate sex at an early age. The interaction between gender and residence shows that female youth in urban areas were less likely to initiate early sexual debut $(\mathrm{OR}=0.34 ; 95 \% \mathrm{CI} 0.14-0.86)$. We also found that females affiliated with the wealthiest households have a lower likelihood of initiating early sexual debut $(\mathrm{OR}=0.15 ; 95 \% \mathrm{CI} 0.04-0$ .51). Additionally, youth resident in urban areas whose households are wealthy are found to be less likely to initiate early debut $(\mathrm{OR}=0.10 ; 95 \% \mathrm{CI} 0.02-0.44)$. However, a-3 way interactive effective revealed that female youth resident in urban areas whose households are wealthy were found to be more likely to initiate early debut ( $\mathrm{OR}=8.27$; 95\%CI 2.77- 10.69) (See Table 2). 


\section{[INSERT TABLE 2 HERE]}

\section{Discussion}

This study was conducted to examine the interactive effect of gender, rural-urban residence, and socioeconomic status on early sexual debut among young adults in Ghana. As reported in other studies (Ningpuanyeh and Susuman 2017; Asante et al. 2018; Zuma et al. 2010; Peltzer 2010), the current study found that female youth living in urban areas were less likely to initiate early sexual debut. This suggests that being a young female and living in urban areas is protective of sexual debut. Traditionally, within African cultures, traditional norms generally encourage sexual freedom for males than females (Silberschmidt, 2005). However, there are some evidence to suggest that a growing number of young females initiate sex very early and do so without contraceptives, thereby contributing to the high rate of teenage pregnancy within rural communities (Omane-Adjepong et al. 2012; Gyesaw and Ankomah 2013) and even in some urban cities (Glover et al. 2003). Females living in rural areas are generally known to have late sexual debut compared to males but at the same time their lack of access to reproductive health services in such communities may compel them to yield to social pressure to experiment with sex either for material gain or for negotiating femininities particularly in communities which practice child betrothal (Asante et al. 2018; Alhassan 2013). On the contrary, access to reproductive health information particularly in the media, strong advocacy for girl-child education and children's rights within the urban cities could possibly help delay sex among young females or discourage sexual exploitation of underaged females.

Our findings also suggest female youth from the wealthiest households were less likely to initiate early sexual debut. Within sub-Saharan Africa, inadequate financial resource induces individuals particularly females to engage in transactional sex to attenuate the effect of poverty (Miller et al. 2011; Masa et al. 2018; Marston et al. 2013; Stephenson et al. 2014; Zuma et al., 2010). This therefore means that those adolescents from poor households may likely experience early sexual activity. This finding may also lend support to the assumption that disadvantaged female may engage in sexual debut in order to have access to cash and gifts (Alhassan, 2013; Madise et al. 2007; Masa et al. 2018). Several factors may account for this findings. First, the initiation of early sex for adolescents from poor families could be due to early sexual socialisation 
and the lack of adequate accommodation for such families, which could lead to situations where adolescents sleep in the same room as their parents (Madise et al. 2007; Somefun et al. 2019). For such reasons, early sexual debut or sexual behaviour in general for young females from such background s could thus be a product of social learning. Second, females from wealthy home may have access to assertive building information and sexual education that would enable them to take appropriate decision for their sexual life including early sex. Furthermore, a study has found that issues of sexual and reproductive health such as pregnancy, childbearing and abortion among adolescents and young females attract strong social stigma and discrimination in Ghana (Hall et al. 2015). It is most likely that socialisation within wealthy families for adolescents and younger females will be targeted at fostering life choices that will ensure preservation of family image. Parents from wealthy households may likely invest towards keeping their female wards in school as means of enhancing their life options, averting early sexual debut and its social consequences. On the contrary, the lack of sexual health information and skills in young adults from poor households coupled with the fact that their parents might not be able to meet both material and educational needs may compel them to engage in early sex for transactional purposes (Alhassan 2013). Such adolescents may thus prioritise activities that may lead to the satisfaction of immediate needs such as early sex without thinking of the long term consequences of such behaviours.

Furthermore, youth resident in urban areas whose households are wealthy were found to be less likely to initiate early debut. It is common knowled ge that indices of socioeconomic status, such as parental wealth and education are protective factors for early sexual debut generally among adolescents and young adults. This association may seem to be stronger among young adults in the urban centres mainly due to increased access to reproductive health information and opportunities for personal growth including schooling, sports, entertainment. Being aware of the consequences of early sexual debut and risky sexual behaviours on family, career path and peer relations, it is highly probable that the youth who are from wealthy households and are in the urban centres may delay sex for most of the reasons cited above.

Finally, we found that once gender, residence, and wealth are controlled for, with or without other control variables, female youth in urban areas who are affiliated with households in the upper third of wealth status have a higher likelihood to engage in early sexual debut. This finding is intriguing and revealing. Intriguing primarily due to several opportunities members in this demographic group have in terms of accessibility to sexual health information both in 
electronic and print media, life opportunities such as education and even gender mainstreaming and empowerment programmes within the cities. What is revealing about this finding is the fact that the enormity of opportunities these persons have seems to put them at risk for early sexual debut. Possibly, rather than starting sex early for transactional purposes, females within wealthy households and are in the urban centers may be engaging in early sex for adventure or perhaps experimental purposes. However, unlike their rural poor counterparts, access to sexual health information may perhaps contribute to safe sex practices including use of condoms and contraceptives to prevent STI's and pregnancy (Asante et al. 2018). Again, it is also possible that females in this demographic groups may be having easy access to sexual contents through their use of smartphones, which might impact negatively on them and potentially increase desire for sex at early ages. For instance, a study in Ghana showed that female college students who use WhatsApp are more likely to react negatively to sexual contents they receive as well as receive negative reaction from people they share sexual contents in comparison to their male counterparts (Adu-Kumi 2016). Given that social media applications are usable through stable, high speed internet connectivity, and the fact that these applications are hosted mainly on smartphones, the cost associated with the use of such applications via smartphones may be out of reach of the rural poor. We can presume that early sexual debut is gradually becoming a problem for the contemporary urban rich females.

Findings from this study can also be elucidated within Bronfenbrenner's (1979) ecological model, which integrates the individual, family, and social system forces in explaining behaviors. Though originally focused on adolescents, the ecological theory sheds light on how factors influencing human behavior are multilayered and do interact. Finding of this study reveals such interactions between gender, residence, and wealth status, which thus suggests combined forces at the individual, micro, and meso levels in early sexual debut behaviors. From an intersectional perspective (Crenshaw, 1990), it is evident that vulnerability to early sexual debut is not unidimensional, but multidimensional arising out of the overlapping roles of gender and different axes of identities such as residence and wealth status. Seeing this study's findings in the lenses of both the ecological model and the intersectional theory gives some key insights for prevention of early sexual debut including a focus on multifactorial approaches. Thus, rather than focusing on gender-based, residential, and wealth factors in the behaviour individually, the need for prioritising 
the interactive effect of these factors on the behaviour and how these effects can be significantly minimized may be essential.

The findings of this study have key implications for reproductive sexual health advocacy campaigns including the need to re-examine how challenges and opportunities the urban rich young females face impact on their reproductive and sexual health practices. These findings will have relevance for addressing specific needs of sexually active youth in general, taking into consideration also, how their lived socioeconomic and socio-spatial situations combine with their gender to either increase or decrease their vulnerabilities to early exposure to sex.

Although our study revealed possible interaction effect of gender, residence and socioeconomic status on young adult sexual debut, our study has some limitations. First, the crosssectional nature of the data weakens the evidence of causal relationships. Second, the study relied on self-report measures, which could be affected by social desirability bias or memory bias. Thirdly, our measure of sexual debut excludes other potential variables such as social control, social learning and problem behaviour that have been shown to influence timing of sexual debut. Future research should address these shortfalls to achieve a better understanding of the interactive effect of gender, residence and socio-economic status on young adult sexual debut. Despite these limitations, our study has compelling strengths. The large sample size gave the study sufficient power and the representativeness of the sampling strategy as well as the nationwide nature of the data boosts the study's generalizability to other settings.

\section{Conclusion}

This study was conducted to examine the interactive effect of gender, residence and socioeconomic status on young adult sexual debut using the 2014 Ghana Demographic and Health Survey. The interactive effective revealed the rich wealthiest urban girl had higher likelihood of sexual debut. This study contributes to the scanty literature on the interactive or multiple pathways to early sexual debut among young adults in Ghana and sub-Saharan Africa in general. A genderbased sexual and reproductive health interventions and programmes may be more appropriate for adolescent females in rich households living in urban areas. These intervention should reach these teenagers before they start engaging in sexual intercourse. 


\section{References}

Adu-Kumi B (2016). Sexuality going viral: using WhatsApp as a site for sexual exploration among college students in Ghana. Dissertation, University of Oregon

Alhassan E (2013). Early marriage of young females: A panacea to poverty in the northern region of Ghana. Res Human Soc Sci 3:18-30

Amo-Adjei J, Tuoyire DA (2018). Timing of sexual debut among unmarried youths aged 15-24 years in sub-Saharan Africa. J Biosoc Sci, 50:161-177. https://doi.org/10.1017/S0021932017000098

Asante, KO, Nketiah-Amponsah E, Andoh-Arthur J et al (2018). Correlates of early sexual debut among sexually active youth in Ghana. Int Q Community Health Edu 39:9-17. https://doi.org/10.1177/0272684X18811016

Bronfenbrenner U (1979). The ecology of human development: Experiments by nature and design. Cambridge, MA: Harvard University Press.

Borges ALV, Fujimori E, Kuschnir MCC et al (2016). ERICA: sexual initiation a contraception in Brazilian adolescents. Rev Saude Publ, 50:15s. https://doi.org/10.1590/S01518$\underline{8787.2016050006686}$

Chow EP, Wigan R, McNulty A et al (2017). Early sexual experiences of teenage heterosexual males in Australia: a cross-sectional survey. BMJ Open, 7 http://dx.doi.org/10.1136/bmjopen-2017-016779

Clark S, Koski A, Smith-Greenaway E (2017). Recent trends in premarital fertility across SubSaharan Africa. Stud Fam Plann, 48: 3-22. https://doi.org/10.1111/sifp.12013

Crawford M, Popp D (2003). Sexual double standards: A review and methodological critique of two decades of research. J Sex Res 40:13-26. https://doi.org/10.1080/00224490309552163

Crenshaw, K. (1990). Mapping the margins: Intersectionality, identity politics, and violence against women of color. Stan L Rev, 43: 1241-1299.doi: 10.2307/1229039. 
e Silva RNA, Wijtzes A, van de Bongardt D et al (2016). Early sexual intercourse: Prospective associations with adolescents physical activity and screen time. PLOS One, 11:e0158648. https://doi.org/10.1371/journal.pone.0158648

França MTA, Frio GS (2018) Factors associated with family, school and behavioral characteristics on sexual initiation: A gender analysis for Brazilian adolescents. PLoS ONE 13: e0208542. https://doi.org/10.1371/journal.pone.0208542

Ghana Statistical Service (GSS) (2014) Ghana Demographic and Health_Survey. Accra: Ghana Statistical Service

Glover EK, Bannerman A, Pence BW et al (2003). Sexual health experiences of adolescents in three Ghanaian towns. Int. Fam Plan Perspect 29:32-40. https://www.jstor.org/stable/3180999

Gyesaw NY, Ankomah A (2013). Experiences of pregnancy and motherhood among teenage mothers in a suburb of Accra, Ghana: A qualitative study. Int J Women's Health 5:773. https://doi.org/10.2147/IJWH.S51528

Hall KS, Manu A, Morhe E et al (2015). Understanding "Bad Girl": Stigma and adolescent sexual and reproductive health in Africa. Contraception, 92:393-394. https://doi.org/10.1016/i.contraception.2015.06.158

Jesmin SS, Cready, CM (2016). Community influences on married women's safer sex negotiation attitudes in Bangladesh: A multilevel analysis. Arch Sex Behav 45:383-393. https://doi.org/10.1007/s10508-015-0572-7

Kastbom, ÅA, Sydsjö G, Bladh M et al (2015). Sexual debut before the age of 14 leads to poorer psychosocial health and risky behaviour in later life. Acta Paediatr 104:91-100. https://doi.org/10.1111/apa.12803

Kreager, D. A., Staff, J., Gauthier, R et al (2016). The double standard at sexual debut: Gender, sexual behavior and adolescent peer acceptance. Sex Roles 75:377-392. https://doi.org/10.1007/s11199-016-0618-x

Lara LA, Abdo CH (2016). Age at time of initial sexual intercourse and health of adolescent girls. J Pediatr Adolesc Gynecol 29:417-423. https://doi.org/10.1016/j.jpag.2015.11.012 
Lee RL, Yuen Loke A, Hung TT et al. (2018). A systematic review on identifying risk factors associated with early sexual debut and coerced sex among adolescents and young people in communities. J Clin Nurs 27:478-501. https://doi.org/10.1111/jocn.13933

Lohman BJ, Billings A (2008). Protective and risk factors associated with adolescent boys' early sexual debut and risky sexual behaviors. J Youth Adolesc 37:723. https://doi.org/10.1007/s10964-008-9283-x

Lyons, H. A., Manning, W. D., Longmore, M. A., \& Giordano, P. C. (2014). Gender and casual sex from adolescence to young adulthood: Social and life course correlates. J Sex Res 52: 543-557. https://d oi.org/10.1080/00224499.2014.906032

MacPherson EE, Sadalaki J, Njoloma M et al (2014). Transactional sex and HIV: understanding the gendered structural drivers of HIV in fishing communities in Southern Malawi. J Int AIDS Soc 15:17364. https://doi.org/10.7448/IAS.15.3.17364

Madise N, Zulu E, Ciera J (2007). Is poverty a driver for risky sexual behaviour? Evidence from national surveys of adolescents in four African countries. Afr J Reprod Health, 11:83-98. https://hdl.handle.net/10520/EJC134435

Marston, M., Beguy, D., Kabiru, C., \& Cleland, J. (2013). Predictors of sexual debut among young adolescents in Nairobi's informal settlements. Int Perspect Sexual Reprod Health 39:22-31. doi:10.1363/3902213

Masa R, Chowa G, Sherraden M. (2019). An Evaluation of a school-based savings program and its effect on sexual risk behaviors and victimization among young Ghanaians. Youth Soc. Online First https://doi.org/10.1177/0044118X18824730

Miller CL, Bangsberg DR, Tuller DM et al. (2011). Food insecurity and sexual risk in an HIV endemic community in Uganda. AIDS Behav15:1512-1519. https://doi.org/10.1007/s10461-010-9693-0

Ningpuanyeh WC, Sathiya Susuman A (2017). Correlates of early sexual debut and its associated STI/HIV risk factors among sexually active youths in Malawi. J Asian Afr Stud 52:1213-1224. https://doi.org/10.1177/0021909616654300 
Omane-Adjepong M, Oduro FT, Annin K (2012). A multinomial regression analysis of unplanned pregnancies in Ahafo Ano South District, Ghana. Am Int J Contemp Res 2:9097.

Onsomu EO, Kimani JK, Abuya BA et al (2013). Delaying sexual debut as a strategy for reducing HIV epidemic in Kenya. Afr J Reprod Health, 17:46-57. https://hdl.handle.net/10520/EJC135263

Peltzer K (2010). Early sexual debut and associated factors among in-school adolescents in eight African countries. Acta Paediatr 99:1242-1247. https://doi.org/10.1111/j.1651$\underline{2227.2010 .01874 . x}$

Rose A, Koo HP, Bhaskar B et al (2005). The influence of primary caregivers on the sexual behavior of early adolescents. J Adolesc Health, 37:135-144. https://doi.org/10.1016/j.jadohealth.2005.02.009

Santelli J, Ott MA, Lyon M et al (2006). Abstinence and abstinence-only education: A review of US policies and programs. J Adolesc Health 38:72-81. https://doi.org/10.1016/j.jadohealth.2005.10.006

Silberschmidt M. (2005) Poverty, male disempowerment, and male sexuality: Rethinking men and masculinities in rural and urban East Africa. In: Ouzgane L., Morrell R. (eds) African Masculinities. Palgrave Macmillan, New York

Somefun OD, Odimegwu C, Simo Fotso A et al (2019). Union formation among youth in subSaharan Africa: Does early sexual debut matter?. Emerg Adulthood. https://doi.org/10.1177/2167696818817905

Stephenson R, Simon C, Finneran C (2014). Community factors shaping early age at first sex among adolescents in Burkina Faso, Ghana, Malawi, and Uganda. J Health, Popul Nutr 32:161-175.

Zuma K, Setswe G, Ketye Y et al (2010). Age at sexual debut: a determinant of multiple partnership among South African youth. Afr J Reprod Health, 14(2), 47-54. 


\section{LIST OF TABLES}

Table 1: Demographic characteristics of the sample $(N=2,746)$

\begin{tabular}{|c|c|c|}
\hline Variables & Frequency & $\%$ \\
\hline \multicolumn{3}{|l|}{ Gender } \\
\hline Male & 670 & 24.4 \\
\hline Female & 2,076 & 75.6 \\
\hline \multicolumn{3}{|l|}{ Age } \\
\hline 20-24 years & 1,827 & 66.5 \\
\hline 15-19 years & 919 & 33.5 \\
\hline \multicolumn{3}{|l|}{ HIV testing status } \\
\hline Untested & 1,730 & 63.0 \\
\hline Tested & 1,016 & 37.0 \\
\hline \multicolumn{3}{|l|}{ Employment status } \\
\hline Unemployed & 1,147 & 41.8 \\
\hline Employed & 1,599 & 58.2 \\
\hline \multicolumn{3}{|l|}{ Ethnicity } \\
\hline Akan & 1,175 & 42.9 \\
\hline Ga-Adangme & 155 & 5.6 \\
\hline Ewe & 328 & 11.9 \\
\hline Mole Dagbani & 624 & 22.7 \\
\hline Other & 464 & 16.9 \\
\hline \multicolumn{3}{|c|}{ Contraception method } \\
\hline Modern & 685 & 24.9 \\
\hline Traditional & 159 & 5.8 \\
\hline None & 1,902 & 69.3 \\
\hline \multicolumn{3}{|l|}{ Educational Level } \\
\hline No education & 275 & 10.0 \\
\hline Basic education & 500 & 18.2 \\
\hline At least secondary & 1,971 & 71.8 \\
\hline \multicolumn{3}{|l|}{ Access to media } \\
\hline None & 189 & 6.9 \\
\hline Partial access & 1,981 & 72.1 \\
\hline Full access & 576 & 21.0 \\
\hline \multicolumn{3}{|l|}{ Religious affiliation } \\
\hline Other & 141 & 5.1 \\
\hline Christian & 2,106 & 76.7 \\
\hline Muslim & 499 & 18.2 \\
\hline \multicolumn{3}{|l|}{ Wealth status } \\
\hline Poor & 1,238 & 45.1 \\
\hline Average & 658 & 24.0 \\
\hline Rich & 850 & 30.9 \\
\hline \multicolumn{3}{|l|}{ Place of residence } \\
\hline Rural & 1,490 & 54.2 \\
\hline Urban & 1,256 & 45.8 \\
\hline
\end{tabular}

Source: Computed by authors from 2014 GDHS 
Table 2. Odds ratios from logistic regression on the interactive effect of gender, residence, and wealth status on early sexual debut

\begin{tabular}{|c|c|c|c|c|c|c|c|c|}
\hline $\begin{array}{l}\text { Explanatory } \\
\text { Variables }\end{array}$ & $\begin{array}{c}\text { Model 1a } \\
\text { OR (95\% CI }) \\
\end{array}$ & $\begin{array}{c}\text { Model 1b } \\
\text { OR }(95 \% \mathrm{CI})\end{array}$ & $\begin{array}{c}\text { Model 2a } \\
\text { OR }(95 \% \text { CI })\end{array}$ & $\begin{array}{c}\text { Model 2b } \\
\text { OR (95\% CI) }\end{array}$ & $\begin{array}{c}\text { Model 3a } \\
\text { OR }(95 \% \text { CI }) \\
\end{array}$ & $\begin{array}{c}\text { Model 3b } \\
\text { OR }(95 \% \mathrm{CI})\end{array}$ & $\begin{array}{c}\text { Model 4a } \\
\text { OR }(95 \% \text { CI }) \\
\end{array}$ & $\begin{array}{c}\text { Model 4b } \\
\text { OR }(95 \% \mathrm{CI}) \\
\end{array}$ \\
\hline Female & $\begin{array}{c}1.39 \\
(0.99-1.93)\end{array}$ & $\begin{array}{c}1.16 \\
(0.78-1.74)\end{array}$ & $\begin{array}{c}1.85 \\
(1.31-2.60) * * *\end{array}$ & $\begin{array}{c}1.48 \\
(0.96-2.29)\end{array}$ & & & $\begin{array}{c}1.98 \\
(1.38-2.85)^{* * *}\end{array}$ & $\begin{array}{c}1.77 \\
(1.11-2.83)^{*}\end{array}$ \\
\hline Urban & $\begin{array}{c}0.97 \\
(0.61-1.53)\end{array}$ & $\begin{array}{c}1.15 \\
(0.70-1.89)\end{array}$ & & & $\begin{array}{c}1.27 \\
(0.80-1.99)\end{array}$ & $\begin{array}{c}1.59 \\
(0.90-2.81)\end{array}$ & $\begin{array}{c}1.77 \\
(0.69-4.52)\end{array}$ & $\begin{array}{c}3.64 \\
(1.35-9.84)^{*}\end{array}$ \\
\hline \multicolumn{9}{|l|}{ Wealth index (poor) } \\
\hline Average household & & & $\begin{array}{c}1.00 \\
(0.54-1.85)\end{array}$ & $\begin{array}{c}1.03 \\
(0.55-1.95)\end{array}$ & $\begin{array}{c}0.70 \\
(0.50-0.99)^{*}\end{array}$ & $\begin{array}{c}0.99 \\
(0.68-1.43)\end{array}$ & $\begin{array}{c}0.98 \\
(0.52-1.84)\end{array}$ & $\begin{array}{c}1.46 \\
(0.69-3.09)\end{array}$ \\
\hline Rich household & & & $\begin{array}{c}1.03 \\
(0.64-1.67)\end{array}$ & $\begin{array}{c}1.56 \\
(0.82-2.98)\end{array}$ & $\begin{array}{c}0.51 \\
(0.31-0.83) * *\end{array}$ & $\begin{array}{c}1.14 \\
(0.66-1.95)\end{array}$ & $\begin{array}{c}2.39 \\
(0.84-6.77)\end{array}$ & $\begin{array}{c}4.57 \\
(1.54-8.57) * *\end{array}$ \\
\hline \multicolumn{9}{|l|}{ Gender*Residence } \\
\hline Female*Urban & $\begin{array}{c}0.64 \\
(0.38-1.08)\end{array}$ & $\begin{array}{c}0.69 \\
(0.40-1.21)\end{array}$ & & & & & $\begin{array}{c}0.66 \\
(0.25-1.72)\end{array}$ & $\begin{array}{c}0.34 \\
(0.14-0.86) *\end{array}$ \\
\hline \multicolumn{9}{|l|}{ Gender*Wealth } \\
\hline Average household*Female & & & $\begin{array}{c}0.56 \\
(0.29-1.08)\end{array}$ & $\begin{array}{c}0.73 \\
(0.37-1.43)\end{array}$ & & & $\begin{array}{c}0.67 \\
(0.34-1.33)\end{array}$ & $\begin{array}{c}0.61 \\
(0.26-1.44)\end{array}$ \\
\hline Rich household*Female & & & $\begin{array}{c}0.37 \\
(0.21-0.65) * * *\end{array}$ & $\begin{array}{c}0.42 \\
(0.22-0.79) * *\end{array}$ & & & $\begin{array}{c}0.12 \\
(0.04-0.40)^{* * *}\end{array}$ & $\begin{array}{c}0.15 \\
(0.04-0.51)^{* *}\end{array}$ \\
\hline \multicolumn{9}{|l|}{ Residence $^{*}$ Wealth } \\
\hline Average household $*$ Urban & & & & & $\begin{array}{c}0.66 \\
(0.35-1.26)\end{array}$ & $\begin{array}{c}0.47 \\
(0.23-0.99) *\end{array}$ & $\begin{array}{c}0.72 \\
(0.18-2.95)\end{array}$ & $\begin{array}{c}0.21 \\
(0.05-0.81) *\end{array}$ \\
\hline Rich household *Urban & & & & & $\begin{array}{c}0.77 \\
(0.40-1.52)\end{array}$ & $\begin{array}{c}0.46 \\
(0.20-1.01)\end{array}$ & $\begin{array}{c}0.23 \\
(0.06-0.98) *\end{array}$ & $\begin{array}{c}0.10 \\
(0.02-0.44) * *\end{array}$ \\
\hline 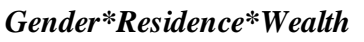 & & & & & & & & \\
\hline Female*Urban*Average & & & & & & & $\begin{array}{c}0.87 \\
(0.20-3.73)\end{array}$ & $\begin{array}{c}2.92 \\
(0.75-11.39)\end{array}$ \\
\hline $\begin{array}{l}\text { Female*Urban* RIch } \\
\text { Other controls }\end{array}$ & No & Yes & No & Yes & No & Yes & $\begin{array}{c}5.27 \\
(2.09-8.35) * \\
\text { No }\end{array}$ & $\begin{array}{c}8.27 \\
(4.77-10.69)^{* * *} \\
\text { Yes }\end{array}$ \\
\hline
\end{tabular}

Note:

$* * * p<0.001 ; * * p<0.01 ; * p<0.05$

${ }^{a}$ Other controls: These include age, HIV testing, employment, ethnicity, religion, contraceptive use, access to media, region a nd education level. 